\title{
Synthesis of new potential ligands for metal complex wires: 2-pyridinmethyl-\{4-[(2-pyridinylmethylimino)-methyl]- benzylidene $\}$ amines
}

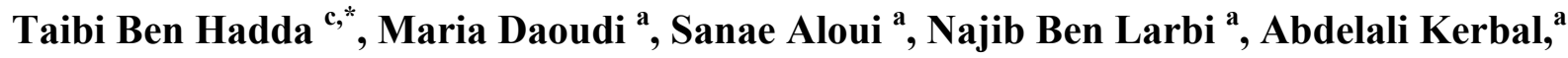 \\ and Abraham Jalbout ${ }^{\text {b }}$ \\ ${ }^{a}$ Laboratoire de Chimie Organique, Faculté des Sciences Dhar El Mehraz, Fès, Morocco \\ ${ }^{b}$ Department of Chemistry, The University of Arizona Tucson, AZ 85721 USA \\ ${ }^{c}$ Laboratoire d'Activation Moléculaire, Faculté des Sciences, 60000 Oujda, Morocc \\ E-mail: tbenhadda@yahoo.fr
}

\begin{abstract}
Two new simple bis-bidentate ligands $\quad N$-(2-pyridinylmethyl)- $N$ - $[(E)-(4-[(2-$ pyridinylmethyl)imino]methylphenyl)methylidene]amine and 4-methyl- $N$-[(E)-(4-[(4-methyl-2pyridinyl)imino]methylphenyl)methylidene]-2-pyridinamine were prepared in good yield by condensation of readily available and inexpensive chemicals; 2-amino-methylpyridine 2 or 2amino-para-methyl-pyridine 4 with terephthaladehyde $\mathbf{1}$. The synthesis and characterization of these two polydentate ligands are described. The thermo-stability of both compounds $\mathbf{3}$ and $\mathbf{5}$ has been calculated.
\end{abstract}

Keywords. Metal wires, bis-bidentate ligands, theoretical calculations, AM1, thermochemistry

\section{Introduction}

Polymetallic complexes with suitable polydentate bridging ligands can be useful models of molecular wires. ${ }^{1}$ By reference to macroscopic electrical devices, the concept of a wire is fundamentally based on intramolecular electron transfer that occurs in its simplest form in mixed-valence complexes. Bimetallic metal complexes with suitable bridging ligands can be useful models to study electronic interaction or electron transfer rates with distance including in biological electron transfer. ${ }^{1}$ Another interesting use of long distance coordinating ligands is the electronic communication between remote metallic atoms and the development of molecular switches, i.e. molecules able to promote or block intramolecular electron transfer. ${ }^{1}$ This development clearly requires the mastering of long-distance electron transfer (over 15-20 A).

In search of new terminal coordinating groups to study intramolecular electron transfers, we have considered the case of polydendate pyrazole ligands. Such compounds are particularly 
interesting as ligands for the building of polynuclear complexes as models for bioinorganic systems ${ }^{2}$ as well as for the discovery of new catalyst precursors. ${ }^{3}$

The flexibility of the pyrazolic N-coordinating groups of the tridentate ligands could allow them to act as meridional ${ }^{4,5}$ or as facial ligands ${ }^{6,7}$ when coordinating to transition metal complexes. In the case of polydentate ligands, they could coordinate in facial and meridional fashion. In contrast, with bis-tridentate ligand, the four nitrogen atoms can not coordinate to the same metal atom and are expected to lead to polymeric metal complex. ${ }^{8-11}$

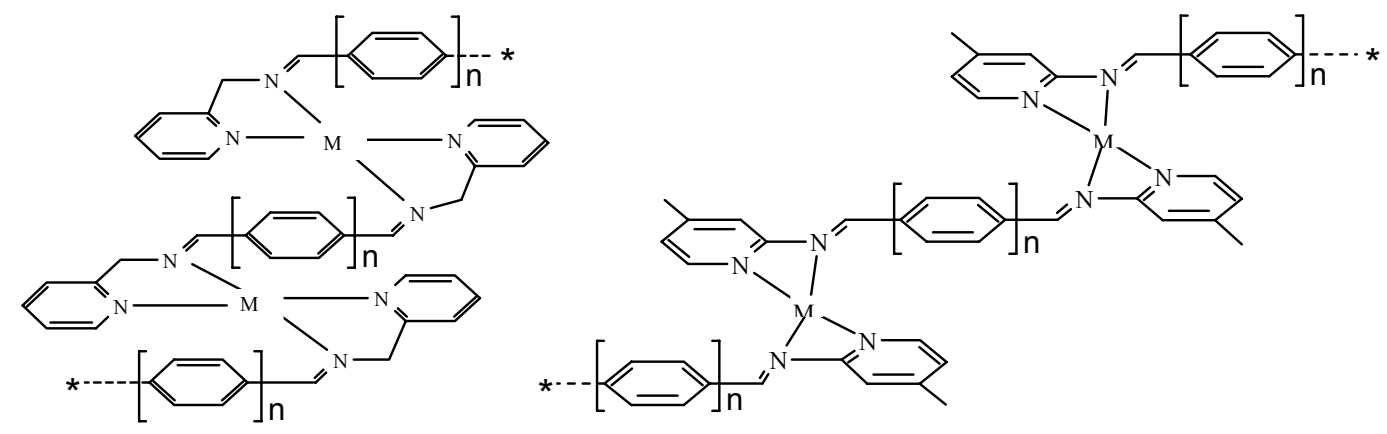

Scheme 1. Polyorganometallic wires in perspectives

To gain insight into the coordination behaviour of larger ligand systems containing at the same time pyrazolyl nitrogen groups and electron releasing amine $\mathrm{N}$-donor atoms we have developed initial work on tridentate $N, N$-bis-[(3,5-dimethyl-1-pyrazolyl)methyl] alkylamines. ${ }^{12-}$ 14

In the present paper, we report the synthesis of two new bis-bidentate ligands containing pyridyl rings bridged by iminomethylphenyl or iminophenyl groups as translator, with the topology shown in Scheme 1 in perspective to win more thermo-stability of future resulting polyorganometallic materials.

\section{Results and Discussion}

\section{Synthesis of ligands 3 and 5}

On the basis of our initial work for the synthesis of polydentate ligands, ${ }^{14}$ the new simple bisbidentate ligands 3 and 5 were prepared on reaction of benzene-1,4-dicarbaldehyde $\mathbf{1}$ and $C$ pyridin-2-yl-methylamine 2 or 2-amino-4-methyl pyridine 4 (Scheme 2). 


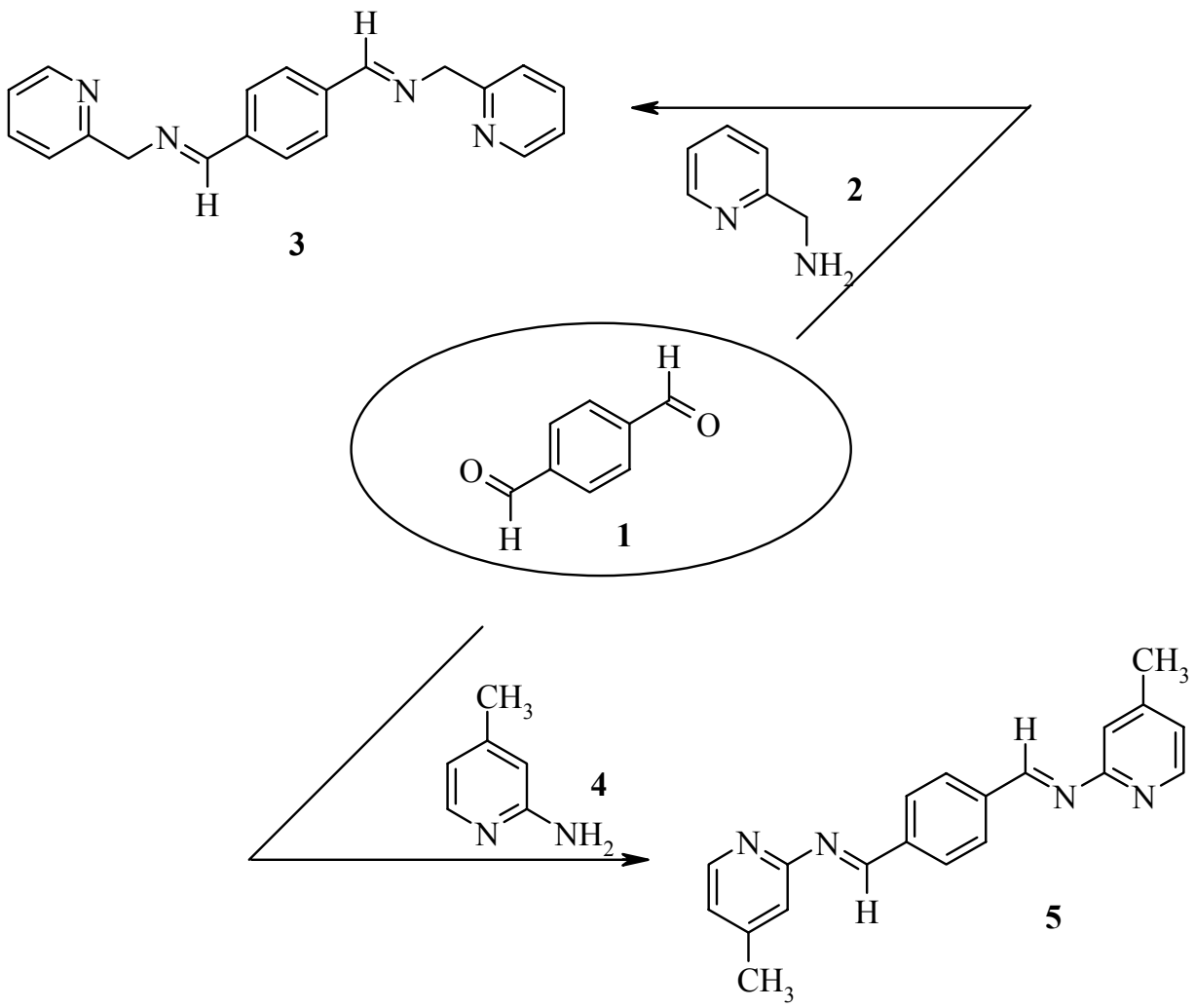

\section{Scheme 2}

By comparison with various bis-bidentate and bis-tridentate ligands for the synthesis of known bimetallic or polymetallic complexes in the literature, ${ }^{17,18}$ we describe here bis-bidentate ligands, for which the synthesis is relatively easy. Their synthesis from benzene-1,4dicarbaldehyde could certainly be generalised to a large variety of other aromatic di-aldehydes. The IR spectra of the aromatic ligands 3 and $\mathbf{5}$ show one weak absorption band around $3000 \mathrm{~cm}^{-}$ 1. This is due to an hydrogen bonded $\mathrm{v}(\mathrm{C}-\mathrm{H})$ in the aromatic structure. Both $\mathrm{C}=\mathrm{N}$ imine and $\mathrm{C}=\mathrm{C}$ groups are respectively visible at 1600 and $1440 \mathrm{~cm}^{-1}$ for compounds $\mathbf{3}$ and $\mathbf{5}$. These bands did not correlate with protonated $\mathrm{C}=\mathrm{N}$ imines, which usually exhibit a variable band in the region 1690-1640 $\mathrm{cm}^{-1}$. From IR spectrum and we can conclude that the compound $\mathbf{3}$ and $\mathbf{5}$ are constituted with aromatic ring and they exist in the principal forms as shown in Scheme3.

In the ${ }^{1} \mathrm{H}-\mathrm{NMR}$ spectrum of $\mathbf{3}$, the chemical shifts for all four methylene $\left(-\mathrm{CH}_{2}-\right)$ protons appears as a singlet at $5.0 \mathrm{ppm}$. The imine $\mathrm{CH}=\mathrm{N}$ protons coincide at $8.5 \mathrm{ppm}$, as singlet. The same thing happens with compound 5; the two methyl groups of 5 appear at $2.30 \mathrm{ppm}$ as singlet, the presence of two singlet peaks with intensities 2 and 6 respectively at 8.44 and $2.3 \mathrm{ppm}$ indicates that the structure of compound $\mathbf{5}$ is well symmetric. 


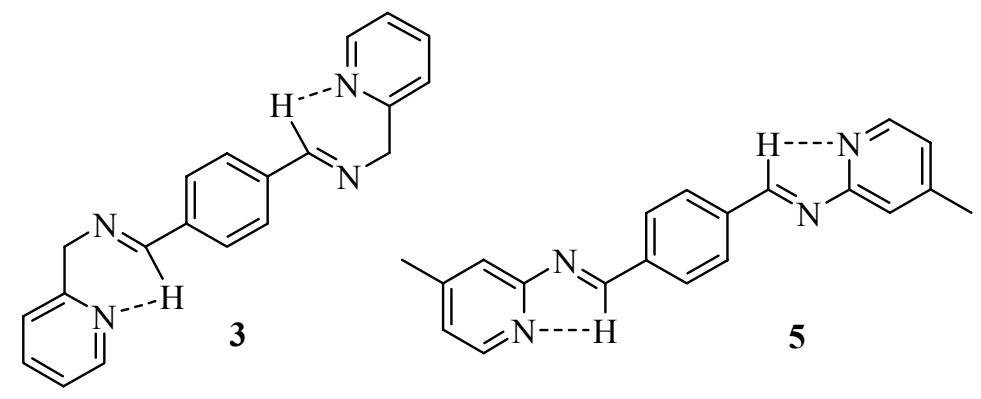

\section{Scheme 3}

The presence of imine (pyridine)--- $\mathrm{HC}=\mathrm{N}$ interaction is preferred over the other possible forms: a six pseudo-membered ring can be formed by an intramolecular tautomeric shift of the imine proton to the nitrogen Nsp2 atom of pyridyl group, generating the stabilised form 3. Similar behaviour could be equally possible at the second nitrogen centre if there is a second imine proton. This leads to a hyper stabilised symmetric bis-didentate ligand that has two different nitrogen centres since the ligand is highly stabilised by intramolecular hydrogen bond and contains a symmetric charge distribution (Scheme 3).

\section{Theoretical Calculations}

In addition to the experiments we performed theoretical calculations. All calculations in this work where carried out with the AM1 level of theory using the GAUSSIAN 03 suite of programs. ${ }^{15}$ More information about these methods is available elsewhere. ${ }^{16}$

The energy of reaction for this is low enough for the reaction to proceed as our calculations suggest, also the compounds have high thermodynamic stability at elevated temperatures. This can be seen from the data in Table 1. Table 2 shows the thermodynamic parameters for the products ( 3 and $\mathbf{5}$ ) where $\mathrm{T}$ (temperature in $\mathrm{K}$ ), $\mathrm{S}$ (entropy in $\mathrm{J} \mathrm{mol}^{-1} \mathrm{~K}^{-1}$ ), $\mathrm{C}_{\mathrm{p}}$ (heat capacity at constant pressure in $\mathrm{kJ} \mathrm{mol}^{-1} \mathrm{~K}^{-1}$ ), and $\Delta \mathrm{H}=\mathrm{H}^{\circ}-\mathrm{H}^{\circ}{ }_{298.15}$ (enthalpy content, in $\mathrm{kJ} \mathrm{mol}^{-1}$ ), $\mathrm{T}_{1}=$ $100 \mathrm{~K}, \mathrm{~T}_{2}=298.15 \mathrm{~K}$, and $\mathrm{T}_{3}=1000 \mathrm{~K}$ calculated AM1 frequencies. The theoretical vibrational spectrum and structure are shown above. In the structure, all bond lengths are in angstroms $(\AA)$ and bond angles are in degrees $\left(^{\circ}\right)$ and the frequencies are in $\mathrm{cm}^{-1}$, and the IR intensities in $\mathrm{KM} / \mathrm{mol}$ (broadened by the Doppler method). These calculations are useful for future thermodynamic studies as well as for NIST database indexing. 
Table 1. Total AM1 energies (hartrees/particle) where $0 \mathrm{~K}$ is the sum of zero-point and electronic energies

\begin{tabular}{|c|c|c|c|c|c|}
\hline \multicolumn{3}{|c|}{ Compound 3} & \multicolumn{3}{|c|}{ Compound 5} \\
\hline & AM1 & AM1 $(0 \mathrm{~K})$ & & AM1 & AM1 $(0 \mathrm{~K})$ \\
\hline \multirow[t]{2}{*}{1} & - & 0.060984 & 1 & -0.0621197 & 0.060984 \\
\hline & 0.0621198 & & & & \\
\hline 2 & 0.0411081 & 0.177988 & 4 & 0.0523671 & 0.160024 \\
\hline \multirow[t]{2}{*}{3} & 0.2175866 & 0.564844 & 5 & & 0.527056 \\
\hline & & & & 0.2373236 & \\
\hline $\mathrm{H}_{2} \mathrm{O}$ & -0.0944289 & -0.073983 & $\mathrm{H}_{2} \mathrm{O}$ & -0.0944289 & -0.073983 \\
\hline${ }^{\mathrm{a}} 1+2+2 \rightarrow 3+$ & 5.417 & 0.0515 & ${ }^{\mathrm{a}} 1+4+4 \rightarrow 5+$ & 3.672 & 1.219 \\
\hline $2 \mathrm{xH}_{2} \mathrm{O}$ & & & $2 \mathrm{xH}_{2} \mathrm{O}$ & & \\
\hline
\end{tabular}

${ }^{\mathrm{a}}$ Energy of reaction $(\mathrm{kcal} / \mathrm{mol})$ leading to the products $\mathbf{3}$ and $\mathbf{5}$ 


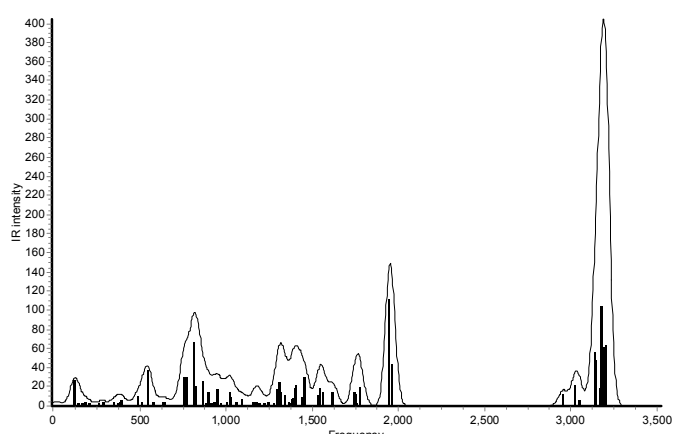

Compound $\mathbf{3}$

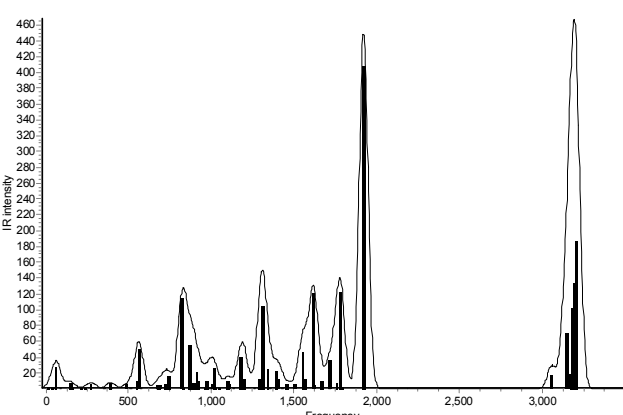

Compound 5

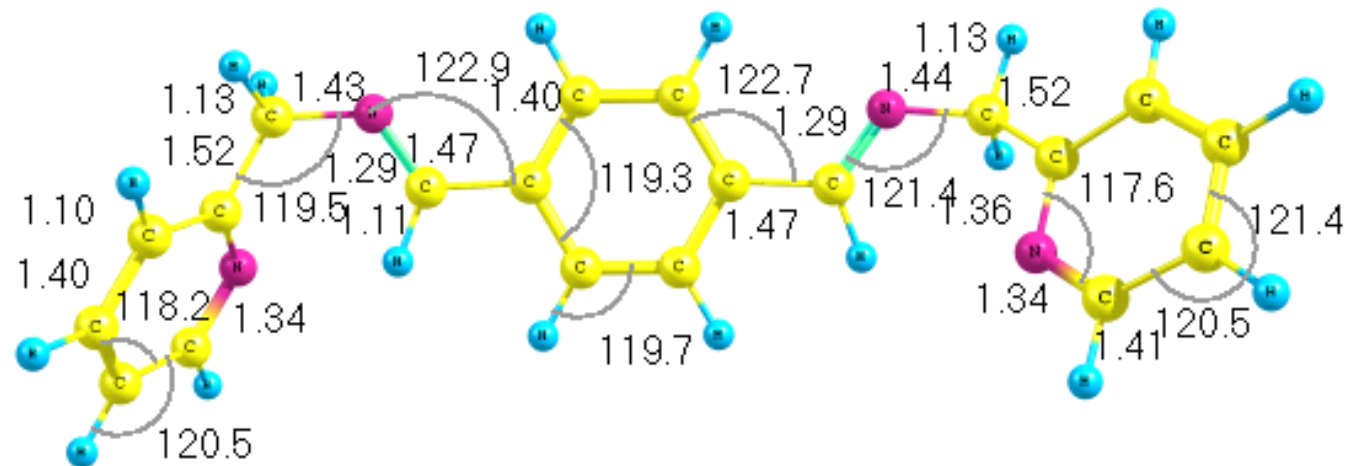

\section{Compound $\mathbf{3}$}

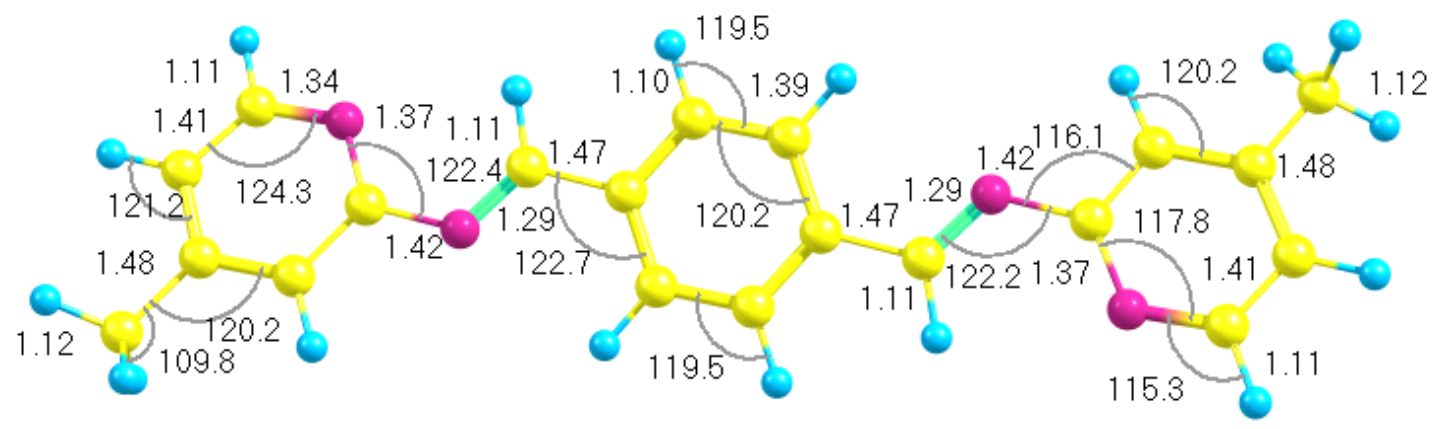

Compound 5

Scheme 3 
Table 2. Physical properties of the molecule as well as vibrational spectra and structure computed at the AM1 level of theory respectively for the products ( $\mathbf{3}$ and $\mathbf{5}$ )

\begin{tabular}{|c|c|c|c|c|}
\hline & Fitted Thermodynamic Equation $(\mathrm{T} / 1000=\mathrm{t})$ & $100 \mathrm{~K}$ & $298.15 \mathrm{~K}$ & $1000 \mathrm{~K}$ \\
\hline $\mathrm{C}_{\mathrm{p}}$ & $\begin{array}{c}-75.01658+1517.40238 * \mathrm{t}-790.85757 * \mathrm{t}^{2} \\
+113.26608 * \mathrm{t}^{3}+0.6796 * \mathrm{t}^{-2}\end{array}$ & 136.47 & 314.65 & 766.92 \\
\hline $\mathrm{S}$ & $\begin{array}{l}-99.63634 * \ln (\mathrm{t})+1608.25223 * \mathrm{t}-891.11127 * \mathrm{t}^{2} / 2 \\
+143.18483 * \mathrm{t}^{3} / 3-1.07688 /\left(2 * \mathrm{t}^{2}\right)+98.49993\end{array}$ & 430.50 & 654.33 & 1308.47 \\
\hline$\Delta \mathrm{H}$ & $\begin{array}{c}-126.4971 * \mathrm{t}+1741.76713 * \mathrm{t}^{2} / 2-1110.25986 * \mathrm{t}^{3} / 3 \\
+258.58982 * \mathrm{t}^{4} / 4-1.34572 / \mathrm{t}+27.21448\end{array}$ & 9.46 & 53.18 & 464.84 \\
\hline $\mathrm{C}_{\mathrm{p}}$ & $\begin{array}{l}-61.62252+1367.552 * \mathrm{t}-781.43947 * \mathrm{t}^{2} \\
+143.6249 * \mathrm{t}^{3}+0.60466 * \mathrm{t}^{-2}\end{array}$ & 127.61 & 284.88 & 669.79 \\
\hline $\mathrm{S}$ & $\begin{array}{c}-82.10489 * \ln (\mathrm{t})+1444.96397 * \mathrm{t}-871.00367 * \mathrm{t}^{2} / 2 \\
+173.30663 * \mathrm{t}^{3} / 3-0.92941 /\left(2 * \mathrm{t}^{2}\right)+137.0439\end{array}$ & 419.83 & 624.92 & 1203.87 \\
\hline$\Delta \mathrm{H}$ & $\begin{array}{c}-102.61888 * \mathrm{t}+1546.86079 * \mathrm{t}^{2} / 2-1038.0619 * \mathrm{t}^{3} / 3 \\
+261.14802 * \mathrm{t}^{4} / 4-1.13493 / \mathrm{t}+23.33127\end{array}$ & 9.12 & 49.08 & 412.29 \\
\hline$\Delta \mathrm{G}$ & $\begin{array}{c}-239.66278 * \mathrm{t}-671.533575 * \mathrm{t}^{2}+65.287005 * \mathrm{t}^{4}- \\
0.670225 / \mathrm{t}+89.4812017 * \mathrm{t}^{3}+105.43616\end{array}$ & -32.863 & -137.24 & -791.58 \\
\hline
\end{tabular}

\section{Experimental Section}

\section{General methods}

Infrared spectra were recorded on a PYE Unicam SP3-300 spectrometer as $\mathrm{KBr}$ pellets. The ${ }^{1} \mathrm{H}$ and ${ }^{13} \mathrm{C}$ NMR spectra were recorded on Bruker spectrometer $(500 \mathrm{MHz})$ using TMS as internal standard. Chemical shifts are reported downfield from the standard in ppm. The FAB mass spectra were obtained on a NERMANG R10-LOC instrument. For the chemical ionisation (DCI/ $\mathrm{NH}_{3} / \mathrm{CH}_{3}$ ), the compounds were dissolved in DMSO or $\mathrm{MeOH}$ and dispersed in a matrix solution, currently the 3-nitrobenzyl (MNBA) or glycerol (GLY).

\section{Synthesis of compounds 3 and 5}

$N$-(2-pyridinylmethyl)- $N$-[(E)(4[(2pyridinylmethyl)imino]methylphenyl)methylidene] amine (3). The product 3 was prepared by the addition of $1.34 \mathrm{~g}$ (10 mmoles) of aromatic dialdehyde (terephthalaldehyde) 1 to $2.16 \mathrm{~g}$ ( $20 \mathrm{mmoles})$ of the amine (2-amino-methylpyridine) 2 previously dissolved in $50 \mathrm{~mL}$ of methanol and the mixture was continued at room temperature for 4-5 days. The formed compound was precipitated alone without adding any solvent, washed with ethylic ether and dried under vacuum. Compound $\mathbf{3}$ was obtained as a white solid (77\% 
yield). M.p. $>260^{\circ} \mathrm{C}$. IR (KBr) $v \mathrm{~cm}^{-1}: 3000,2500,1600,1440.1 \mathrm{H}$ NMR: (CD3CO2D, 500 $\mathrm{MHz}, \delta \mathrm{ppm}): 8.60(\mathrm{~m} .2 \mathrm{H}, 2 \mathrm{~N}=\mathrm{CH}$ py), 8.50 (s, $2 \mathrm{H}, 2 \mathrm{CH}=\mathrm{N}$ imine), 7.75-7.23 (m. $4 \mathrm{H}, \mathrm{Ph})$, 7.25-7.36 (m. $4 \mathrm{H}$, py ), 5.0 (s, $\left.4 \mathrm{H}, 2 \mathrm{CH}_{2}\right) .{ }^{13} \mathrm{C} \mathrm{NMR}\left(\mathrm{CD}_{3} \mathrm{CO}_{2} \mathrm{D}, 500 \mathrm{MHz}, \delta \mathrm{ppm}\right): 162.80$, 157.60, 149.90, 138.26, 137.28, 128.68, 125.24, 123.28, 69.87. SM: (FAB $\left.>0, \mathrm{CH}_{3} \mathrm{CO}_{2} \mathrm{H} / \mathrm{Gly}\right)$. $[\mathrm{M}+\mathrm{H}]^{+}=315(14 \%) ;\left[\mathrm{M}+\mathrm{CH}_{3} \mathrm{CO}_{2} \mathrm{H}\right]^{+}=375(9.6 \%),\left[\mathrm{C}_{5} \mathrm{H}_{4} \mathrm{~N}-\mathrm{CH}_{2}-\mathrm{N}=\mathrm{CH}-\mathrm{C}_{6} \mathrm{H}_{4}=\mathrm{NH}\right]^{+}=223$ (100\%), $\left[\mathrm{C}_{5} \mathrm{H}_{4} \mathrm{~N}-\mathrm{CH}_{2}-\mathrm{N}=\mathrm{CH}-\mathrm{C}_{6} \mathrm{H}_{4}=\mathrm{NH}+\mathrm{CH}_{3} \mathrm{CO}_{2} \mathrm{H}_{2}\right]^{+}=283$ (84.9\%). Anal. Calcd. $\left(\mathrm{C}_{20} \mathrm{H}_{18} \mathrm{~N}_{4}\right)$ : C 76.41, H 5.77, N 17.82; Found: C 76.53, H 5.63, N 18.02\%.

\section{4-methyl- $N$-[(E)-(4-[(4-methyl-2pyridinyl)imino]methylphenyl)methylidene]-2-pyridin}

amine (5). The product 5 was prepared by the addition of $1.34 \mathrm{~g}$ (10 mmoles) of aromatic dialdehyde (terephthalaldehyde) 1 to $2.16 \mathrm{~g}$ (20 mmoles) of the amine (2-amino-4methylpyridine) 4 previously dissolved in $50 \mathrm{~mL}$ of methanol. After few minutes of mixing, $5 \mathrm{ml}$ of formic acid $\left(\mathrm{CH}_{2} \mathrm{O}_{2}\right)$ is added and the solution troubled. The formed compound was precipitated alone without adding any solvent, washed with ethylic ether and dried under vacuum. A. white solid was obtained $\left(\mathbf{5}, 88 \%\right.$ yield). M.p. $>260^{\circ} \mathrm{C}$. IR $(\mathrm{KBr}) v \mathrm{~cm}^{-1}: 2900,2500$, 1600, 1400. ${ }^{1} \mathrm{H}$ NMR: $\left(\mathrm{CD}_{3} \mathrm{CO}_{2} \mathrm{D} ; 500 \mathrm{MHz}, \delta \mathrm{ppm}\right): 8.54$ (m. $2 \mathrm{H}, \mathrm{N}=\mathrm{CH}$ py), 8.44 (s, $2 \mathrm{H}$, $\mathrm{CH}=\mathrm{N}$ imine), $7.80-7.20(\mathrm{~m} .4 \mathrm{H}, \mathrm{Ph}), 7.1-6.5(\mathrm{~m} .4 \mathrm{H}$, pyridine $), 2.3\left(\mathrm{~s}, 6 \mathrm{H}, 2 \mathrm{CH}_{3}\right) .{ }^{13} \mathrm{C} \mathrm{NMR}$ $\left(\mathrm{CD}_{3} \mathrm{CO}_{2} \mathrm{D} ; 500 \mathrm{MHz}, \delta \mathrm{ppm}\right): 162.50,160.30,151.00,145.90,137.80,129.82,121.72,113.67$, 64.44, 21.88, 27.23. SM: $\left(\mathrm{FAB}<0, \mathrm{CH}_{3} \mathrm{CO}_{2} \mathrm{H} / \mathrm{Gly}\right) .[\mathrm{M}+\mathrm{H}]^{+}=315(6.3 \%) ;\left[\mathrm{M}+\mathrm{CH}_{3} \mathrm{CO}_{2} \mathrm{H}\right]^{+}=$ $375(2.9 \%) ;\left[\mathrm{CH}_{3}-\mathrm{N} \mathrm{C}_{5} \mathrm{H}_{3}-\mathrm{N}=\mathrm{CH}-\mathrm{C}_{6} \mathrm{H}_{4}=\mathrm{NH}+\mathrm{CH}_{3} \mathrm{CO}_{2} \mathrm{H}\right]^{+}=283(41.2 \%) ;\left[\mathrm{CH}_{3} \mathrm{~N} \mathrm{C}_{5} \mathrm{H}_{3}-\right.$ $\left.\mathrm{N}=\mathrm{CH}-\mathrm{C}_{6} \mathrm{H}_{4}-\mathrm{CH}=\mathrm{NH}\right]^{+}=223(4 \%) ;\left[\mathrm{N}=\mathrm{CH}-\mathrm{C}_{6} \mathrm{H}_{3}-\mathrm{CH}=\mathrm{NH}+\mathrm{CH}_{3} \mathrm{CO}_{2} \mathrm{H}\right]^{+}=191(68 \%) ;[\mathrm{N}=\mathrm{CH}-$ $\left.\mathrm{C}_{6} \mathrm{H}_{4}-\mathrm{CH}=\mathrm{NH}\right]^{+}=131(100 \%)$. Anal. Calcd. $\left(\mathrm{C}_{20} \mathrm{H}_{18} \mathrm{~N}_{4}\right)$ : C 76.41, H 5.77, $\mathrm{N}$ 17.82; Found : $\mathrm{C}$ 76.37, H 5.65, N $17.92 \%$.

\section{Acknowledgements}

We are indebted to the "Projet Global de Recherche de l'Université Mohamed Premier PGRUMP-BH-2005" and CUD-BH-2007 for financial support.

\section{References and Notes}

1. Launay, J.-P. Chem. Soc. Rev. 2001, 30, 386 and references cited therein.

2. Sorrell, T.N.; Vankai, V.A.; Garrity, M. L. Inorg. Chem. 1991, 30, 207.

3. Togni, A.;Venanzi, L. M. Angew. Chem. Int. Ed. Engl. 1994, 33, 497.

4. Sheu, S.-C.; Tien, M.-J.; Cheng, M.-C.; Ho, T.-I.; Peng, S.-M.; Lin, Y.-C. J. Chem. Soc., Dalton Trans, 1995, 3503.

5. Rodriguez, M.; Romeo, I.; Liobet; A., Deronzier, A.; Biner, M.; Parella, T.; Stoeckli-Evans, H. Inorg. Chem., 2001, 40, 4150. 
6. Palaniandavar, M.; Butcher, R. J.; Addison, A.W. Inorg. Chem. 1996, 35, 467.

7. Romero, I.; Rodriguez, M.; Liobet, A.; Collomb-Dunand-Sauthier, M.-N.; Deronzier, A.; Parella, T.; Stoeckli-Evans, H. J. Chem. Soc., Dalton Trans. 2000, 1689.

8. El Kodadi, M.; Malek, F.; Touzani, R.; Ramdani, A.; El Kadiri, S.; Eddike, D. Molecules 2003, 8, 780 .

9. Lee, S.-A.; Lim, J. W.; Roh, S.G.; Yeo, H. J.; Jeong, J. H. Bull Korean Chem. Soc. 2000, 21, 1271.

10. Alilou, H.; El Hallaoui, A.; El Ghadraoui, H.; Giorgi, M.; Pierrot, M.; Réglier, M. Acta. Crysta. Sect. C 559.

11. Kani, Y.; Ohba, S.; Ito S.; Nishida, Y. Acta Cryst. 2000, C56, e233.

12. Touzani, R.; Ramdani, A.; Ben Hadda, T.; El Kadiri, S.; Maury, O.; Le Bozec H.; Dixneuf, P. H. Synthetic Comm., 2001, 31, 1315.

13. Daoudi, M.; Ben Larbi, N.; Benjelloun, D.; Kerbal, A.; Launay, J. P.; Bonvoisin, J.; Jaud, J.; Mimouni, M.; Ben Hadda, T. Molecules 2003, 8, 269.

14. Daoudi, M.; Ben Larbi, N.; Kerbal, A.; Bennani, B.; Launay, J-P.; Bonvoisin, J.; Ben Hadda, T.; Dixneuf, P.H. Tetrahedron 2006, 62, 3123.

15. Frisch, M. J., et. Al., GAUSSIAN 03, Revision A.1, Gaussian, Inc., Pittsburgh PA, 2003.

16. Foresman, J. B.; Frisch, Æ, Exploring Chemistry with Electronic Structure Methods, $2^{\text {nd }}$ Edition Gaussian, Inc., Pittsburgh, PA, 1996.

17. Sondaz, E.; Jaud, J.; Launay, J.-P.; Bonvoisin, J..Eur. J. Inorg. Chem. 2002, 1924.

18. Maekawa, M.; Minematsu, T.; Konaka, H.; Sugimoto, K.; Kuroda-Sowa, T.; Suenaga, Y.; Munakata, M. Inorg. Chim. Acta 2004, 357, 3456. 